\title{
PROCESSO DE CONGEPÇÃO DO PROJETO ARQUITETÔNICO PARA UMA RESIDÊNCIA UNIFAMILIAR - CASA CAMELO
}

\author{
MACEDO, ANDRÉ LUIS GOMES \\ Arquiteto, MsC., Arquiteto e Engenheiro da Empresa AM-Arquitetura e Engenharia; e-mail: andrelgmacedo@hotmail.com \\ Dissertação desenvolvida no Mestrado Profissional em Arquitetura, Projeto e Meio Ambiente da UFRN \\ Orientador: Prof. Dr. Rubenilson B. Teixeira.
}

\section{RESUMO EXPANDIDO}

Essa proposta arquitetônica para residência unifamiliar de alto padrão que levou em consideração aspectos ambientais sustentáveis de gestão de água, energia e condicionantes bioclimáticas, foi fruto de um mestrado de arquitetura e meio ambiente oferecido pelo PPGAU da UFRN, concluído em julho de 2016. O estudo envolveu pesquisas recentes que levantam prescrições técnicas para se projetar residências, suprindo uma lacuna específica em se absorver, compreender e inserir alguns dos conceitos de sustentabilidade às formas tradicionais do habitar.

Confeccionado na cidade de Serra de São Bento, a $130 \mathrm{~km}$ de Natal-RN, o projeto trouxe ao autor a oportunidade de inserir um olhar mais focado às questões ambientais relativas a uma obra dessa natureza, fazendo-o realizar um debate mais minucioso na formação dos valores do programa de necessidades e na compreensão do lugar onde seria inserido o edifício. O terreno árido, inclinado, pedregoso e distante de um centro urbano, exigia uma proposta adaptada ao local, com materiais não convencionais, mais leves e menos artesanais, que mitigassem os impactos de uma residência sobre aquele meio. Era imprescindível também considerar o futuro consumo de água e energia elétrica do edifício. Batizada de "Casa Camelo", a proposta dá ênfase à autossuficiência frente às concessionárias locais desses dois insumos, seja por meio da captação pluvial alternativa com reuso de água ou pela geração renovável de energia eólica ou fotovoltaica, além da adoção de uma solução que levou em conta as estratégias bioclimáticas sugeridas ao microclima estudado para que, de forma passiva, pudéssemos atingir a satisfação quanto ao conforto ambiental do projeto.

Metodologicamente, a pesquisa foi organizada em quatro fases: levantamento de dados, análise dos mesmos, concepção e elaboração da proposta projetual e redação do memorial com fundamentação das etapas do projeto. Na definição do conceito norteador desse projeto, foram feitas reflexões sobre algo que alegoricamente sintetizasse as premissas atribuídas no programa de necessidades e que funcionasse como articulador de todas as condicionantes em uma materialização simbólica e significativa. Nesse caso, elas foram sintetizadas na expressão "Casa Camelo", aglomerando um triplo conceito adotado neste trabalho: a autossuficiência em água e energia e a adaptabilidade ao clima. Os croquis originais sempre evidenciaram o armazenamento específico de água como necessidade primordial do projeto, por isso, foram inicialmente idealizados dois reservatórios de água que resolveriam nos períodos de seca. 


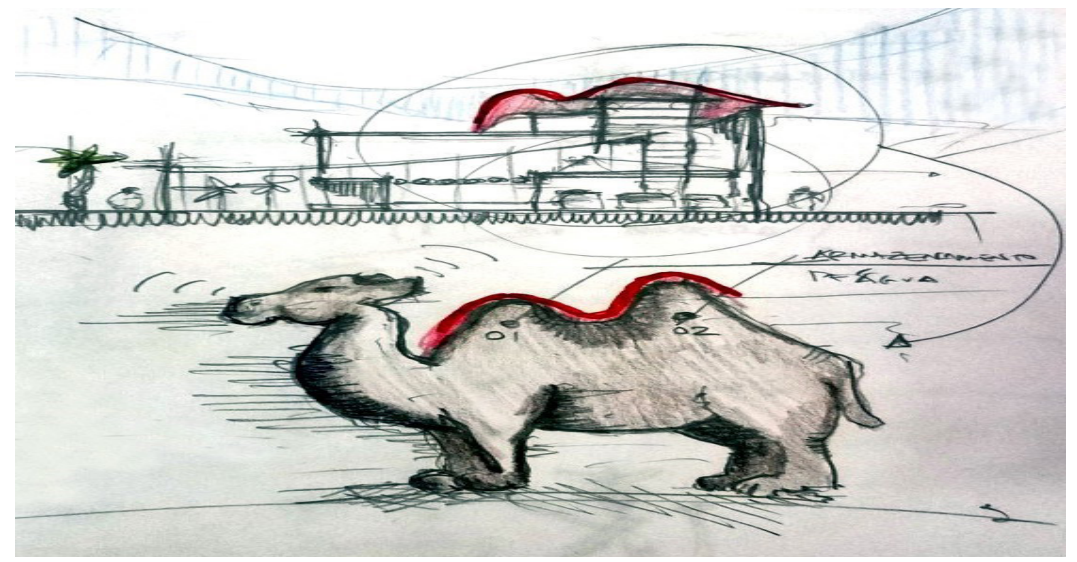

Fonte: Elaboração do Autor (2016)

Realizados os primeiros croquis, com duas caixas d'águas elevadas, imediatamente surgiu a ligação direta com o camelo, mamífero da fauna desértica (figura 1), que tem por maior característica, armazenar água e nutrientes em dois reservatórios externos e superiores a seu corpo, denominados de corcovas, balizando, assim, nosso conceito e nosso próprio partido. Dessa forma, desenvolvemos um quadro ilustrativo presente na figura 2, com nove analogias que materializam e inter-relacionam as características de sustentabilidade do nosso projeto, por meio de croquis dos sistemas construtivos ou soluções previamente pretendidas e as características do camelo, como seu funcionamento fisiológico, físico e comportamental.

Figura 2 - Quadro de materialização do conceito em analogias ao camelo

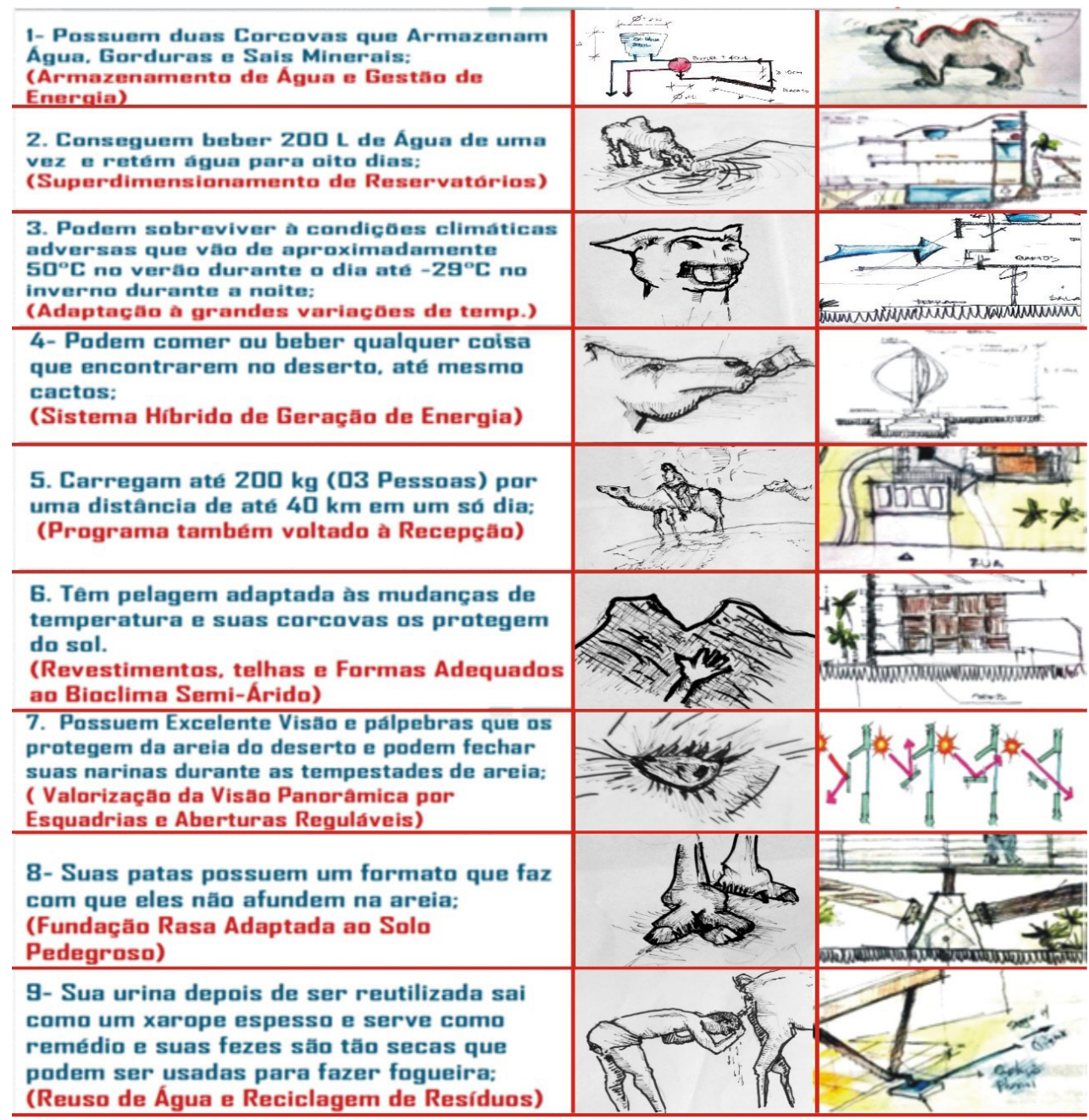


Por ser uma região de altitude elevada, muitas vezes, a água da concessionária não tem pressão de recalque suficiente para abastecer reservatórios superiores e a impossibilidade de se escavar poços tubulares fez com que procurássemos as captações pluviais como solução mais racional. Portanto, nos croquis iniciais, o passo 01, conforme nos mostra a figura 3, foi pontuar ou fazer a locação da caixa d'água como a partida para definição das plantas e dos cortes, ou seja, primeiramente, definimos um ponto para a caixa d'água que, devido à declividade bem acentuada do lote, tomou tendência a ser implantada na frente da casa, onde estão as cotas mais altas da topografia, fazendo melhor uso da gravidade.

Figura 3 - Croquis iniciais de locação da caixa d'água

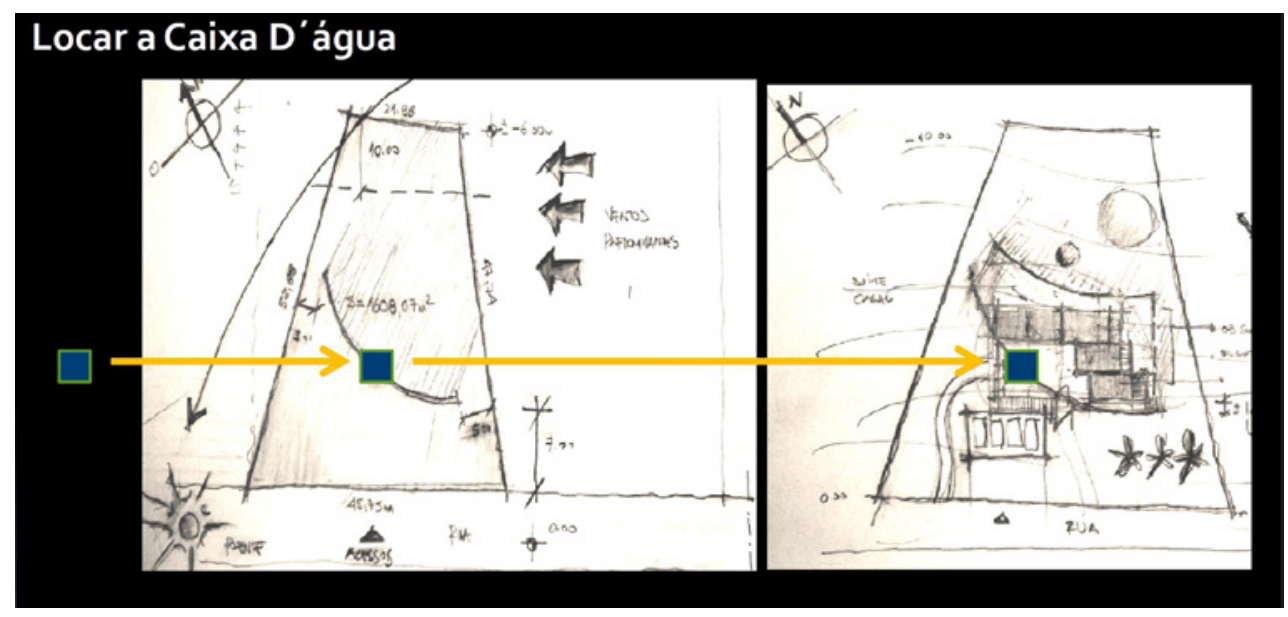

Fonte: Elaboração do Autor (2016)

Por meio das pesquisas, apreendemos as relações do lote com a insolação, com as ventilações naturais e com a topografia. Precisávamos, então, valorizar o belo visual da Serra da Borborema que surge nas costas do lote sem qualquer barreira natural ou artificial. Portanto, as opções seguintes foram de obstrução da fachada frontal noroeste para conter a insolação indesejada, aliada à desobstrução da fachada posterior nordeste, a ser sombreada, ventilada e visualmente bem provida, ou seja, o passo 02 foi obstruir e desobstruir conforme a figura 4 nos mostra.

Figura 3 - Croquis iniciais de locação da caixa d'água

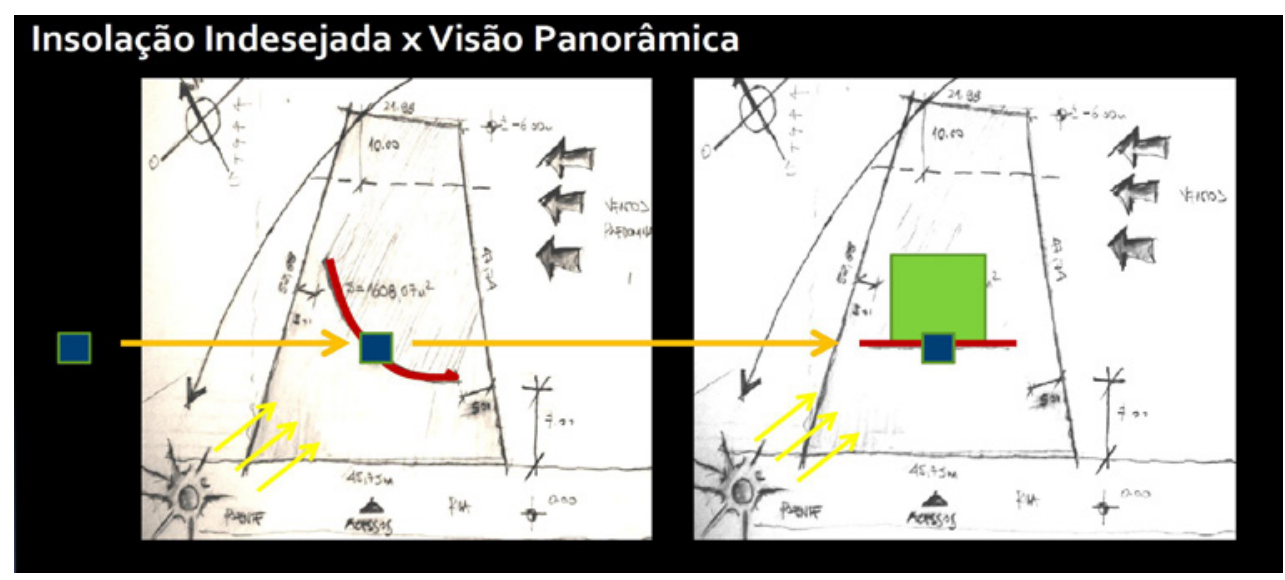

Fonte: Elaboração do Autor (2016)

O último passo veio como a racionalização por ordenamento dos traçados de plantas e elevações, nos quais foram surgindo croquis por cima de uma malha ortogonal de 1,20 x 1,20 m. Isso foi fundamental para a ordenação e alinhamento dos traços retos originalmente solicitados pela estrutura metálica leve sugerida para suportar os painéis cimentícios com essa largura, previamente estabelecida no sistema construtivo a ser adotado. Portanto, a partir da análise dos diversos condicionantes acima expostos, pudemos afirmar que o nosso partido se caracterizou por uma composição mais compactada entre uma caixa d'água em volume vertical, locada na parte alta (frontal) do terreno, e por um volume em forma de "C", cuja parte superior tem o papel fundamental de proteger e sombrear o invólucro. A parte inferior tem a função de sustentar todo o piso, trazendo leveza e graça ao projeto, conforme vimos na figura 5. 


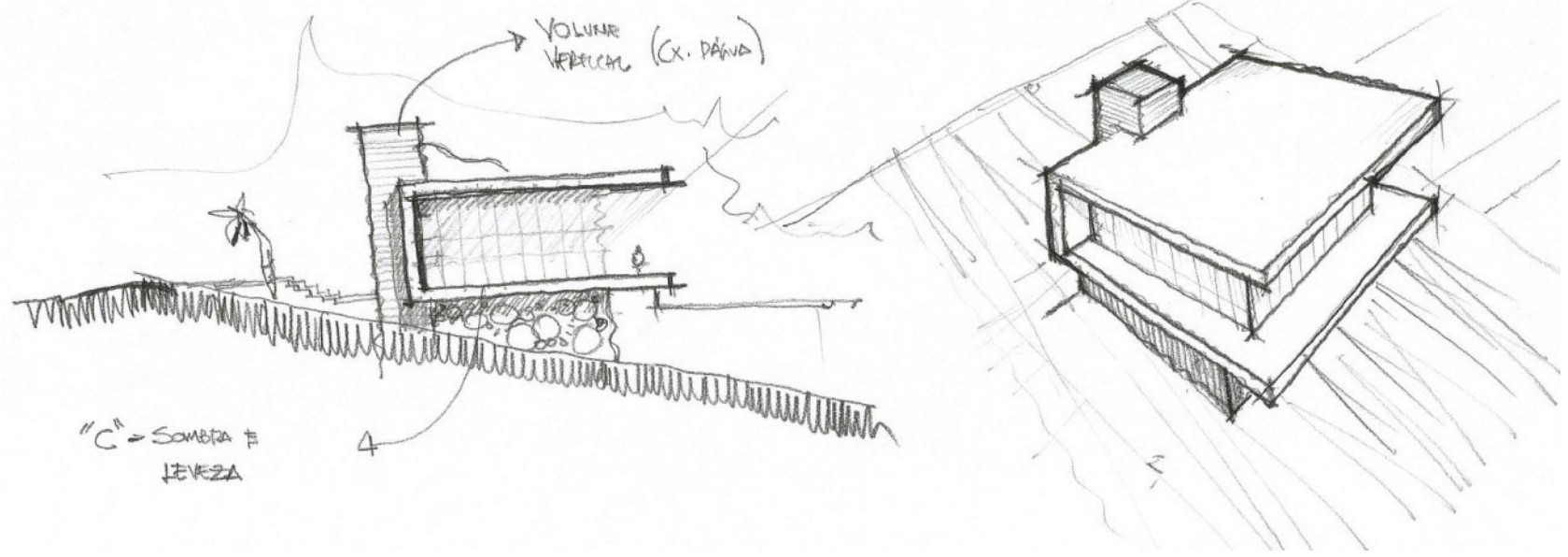

Fonte: Elaboração do Autor (2016)

O partido adotado, como vimos, tendeu a um volume compacto, pois procuramos ter aberturas bem expostas para as fachadas sudeste e nordeste, que também são as fachadas voltadas para a bela visão panorâmica da Serra da Borborema. Dessa forma, conseguimos a união de ventilação natural, sombras vespertinas e vista cenográfica através dessas janelas bem orientadas. Como se trata de uma residência em terreno bem íngreme, não achamos adequado espalhar muito a casa no sentido longitudinal do lote, mas compactar seu layout e suas circulações, pois teríamos que trabalhar com níveis bastante diferentes nos pisos, trazendo desconforto de locomoção e falta de integração entre os ambientes (figura 6).

Figura 6 - Estudos de fachadas e evolução formal do partido
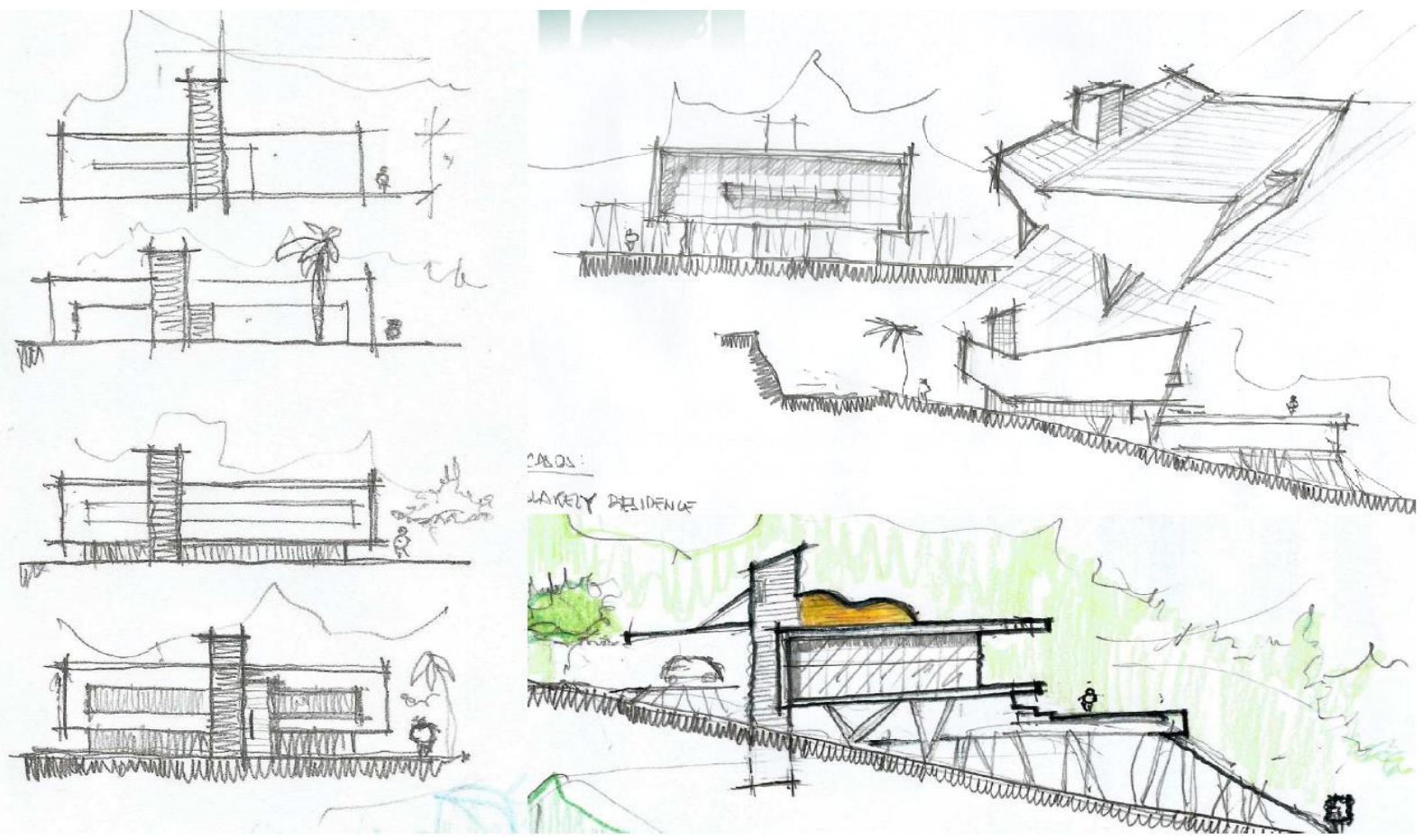

Fonte: Elaboração do Autor (2015)

Com aproximadamente 400,00 m², o projeto dispõe de subsolo, térreo, pavimento superior e cobertura. 0 subsolo possui uma área técnica que acondiciona cinco cisternas pluviais e duas ETE's compactas, com seus devidos reatores, filtros, tanques sépticos, bombas de recalque e piscina e os equipamentos do Sistema Fotovoltaico, além de uma academia de ginástica. A cobertura apresenta a acomodação dos 40 painéis fotovoltaicos, dos 18 coletores de aquecimento da piscina, dos 2 coletores de aquecimento para o boiler, dos 4 condensadores dos condicionadores de ar; além disso, temos a telha termoacústica amarelada que 
acomodará o barrilete e todos os reservatórios de água, sendo 4 pluviais, 1 potável, 1 térmico (boiler) e 1 de reuso. No térreo, percebemos a disposição de ambientes social e da suíte térrea voltadas para as faces sudeste e leste e suas maiores aberturas desfrutando das vantagens microclimáticas dessa orientação. A ligação entre as salas de estar, TV, jantar, cozinhas é quebrada apenas por portas-janelas que integram esses ambientes ao deck e à piscina. Uma peça de vidro translúcido aparece cobrindo um córrego artificial retilíneo de água que nasce do lago frontal sinuoso aflorando no lavabo e seguindo pelo piso até a piscina, criando, na residência, uma sensação de integração entre esses setores da casa. Esses elementos trazem à tona a importância que foi dada à água na concepção arquitetônica criando, ao mesmo tempo, recursos para se resfriar o ar da ventilação vinda do sul e umidificada pelo lago frontal. Na planta do pavimento superior, vemos os dormitórios e suas varandas recebendo os fluxos de ar naturais mais frequentes de sul a nordeste, enquanto que ambientes como o closet e o banheiro do casal (suíte 02), sobrepostos ao setor de serviço térreo, protegem as áreas íntimas da insolação da fachada noroeste (figura 7).

Figura 7 - Planta baixa do subsolo AutoCAD
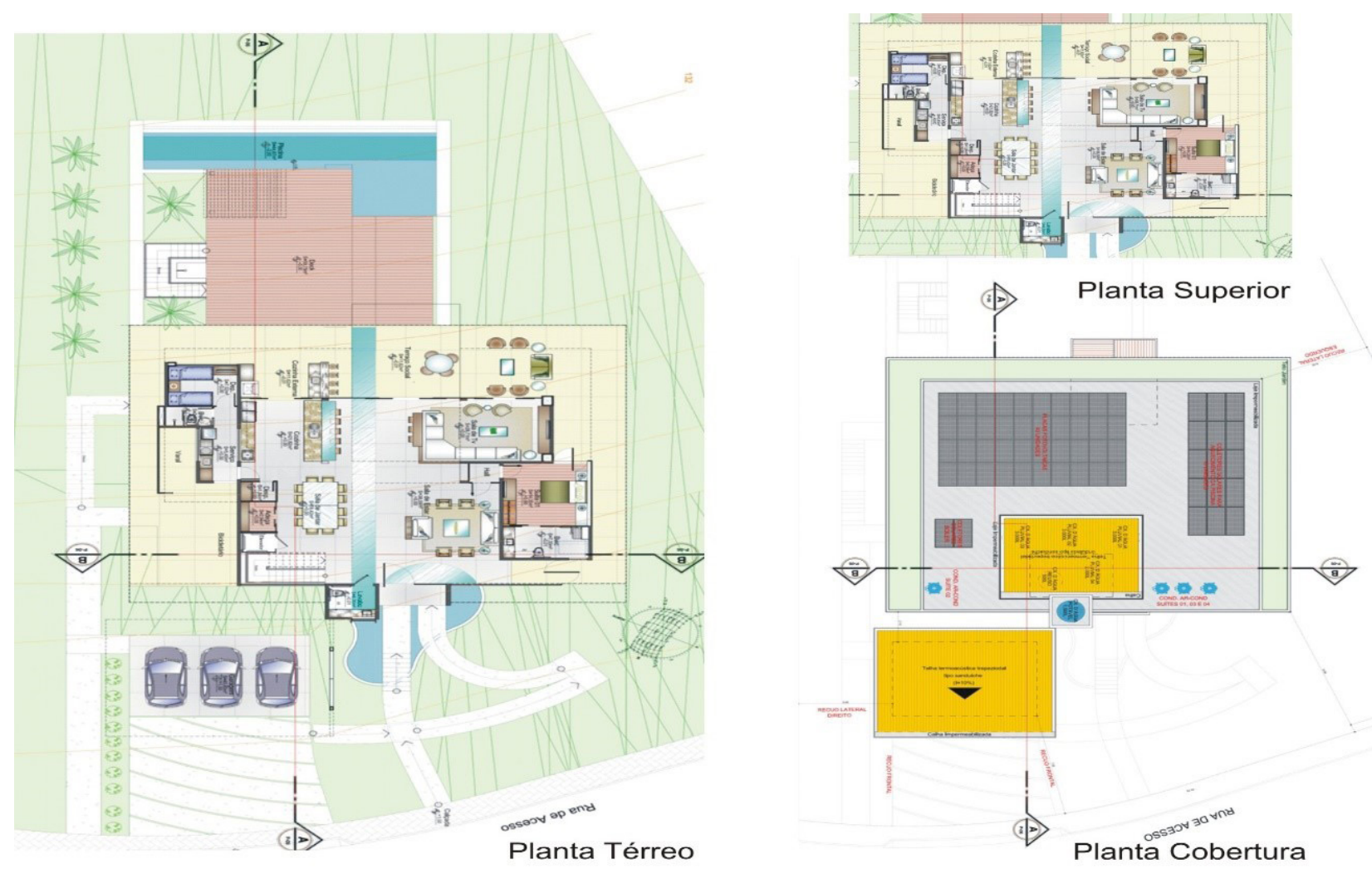

Fonte: Elaboração do Autor (2016)

Todas as imagens da figura 8, apresentada a seguir, representam o resultado formal e dos materiais de acabamento aplicados nas fachadas, escolhidos e justificados no decorrer da pesquisa. A "desobstrução" visual foi obtida pelo uso de esquadrias grandes em vidro e pé-direito alto, que permitem aos visitantes, desde o acesso principal, ter a visibilidade de uma área de lazer e da paisagem esplendorosa que se encontra no pano de fundo, trazendo transparência e clareza à residência. A proposta desenvolvida também trata o projeto como um otimizador de energia, na medida em que foram criadas as condições mais favoráveis, tirando o melhor partido possível, da iluminação e ventilação naturais, como ferramenta de conforto e de racionalização do consumo energético. 
Figura 8 - Perspectivas em 3DS-MAX

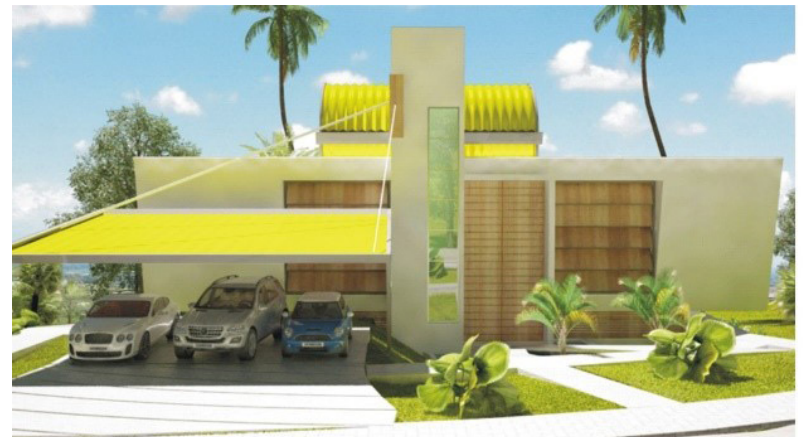

Fachada frontal sudoeste

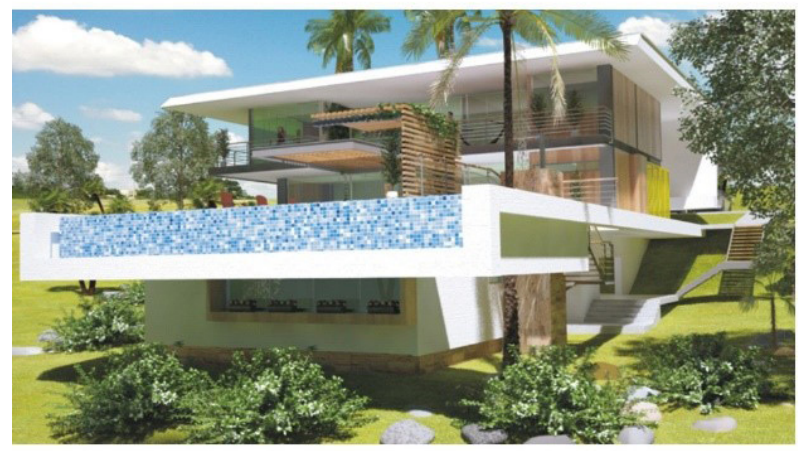

Fachadas posterior/nordeste e lateral esquerda

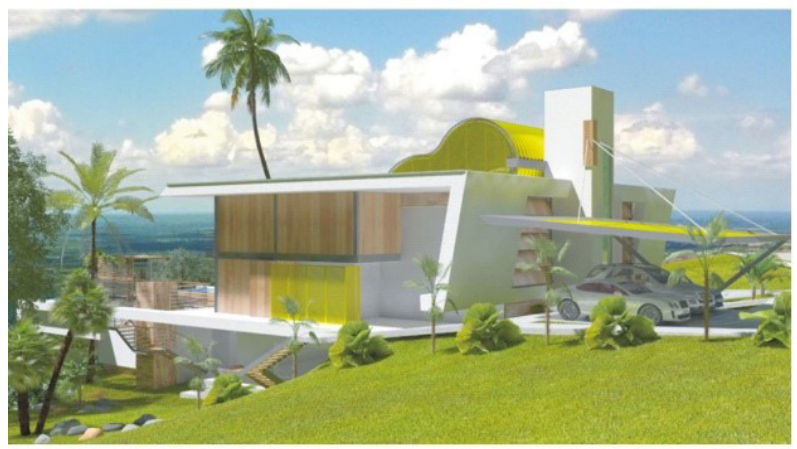

Fachadas lateral esquerda/noroeste e frontal/sudoeste

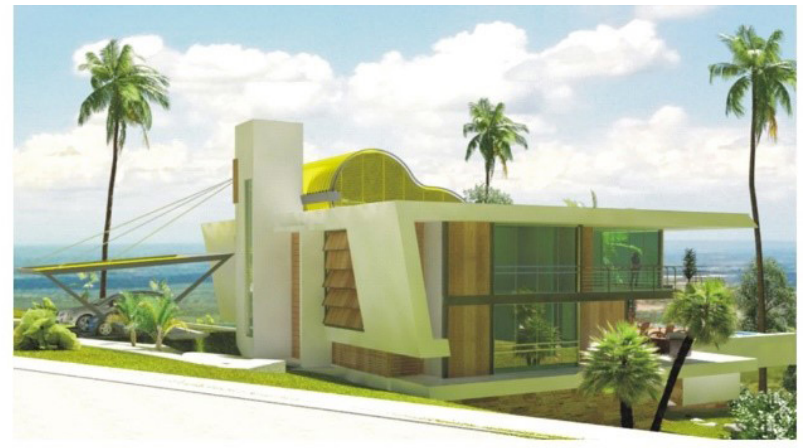

Fachadas frontal/sudoeste e lateral direita/sudeste

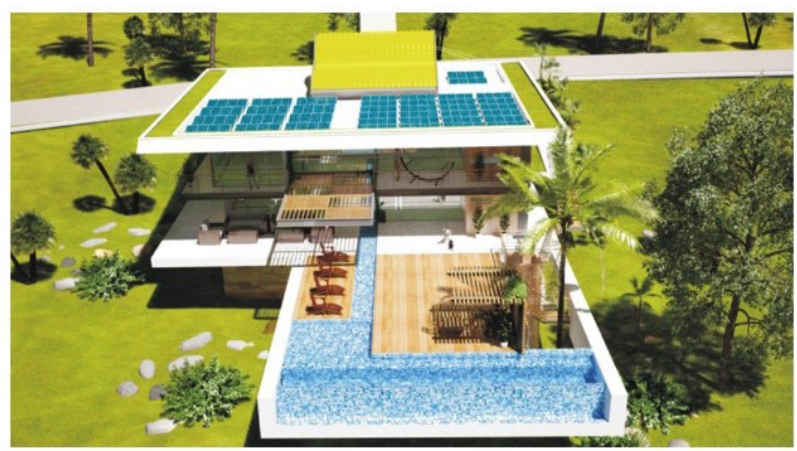

Fachada posterior/nordeste com cobertura

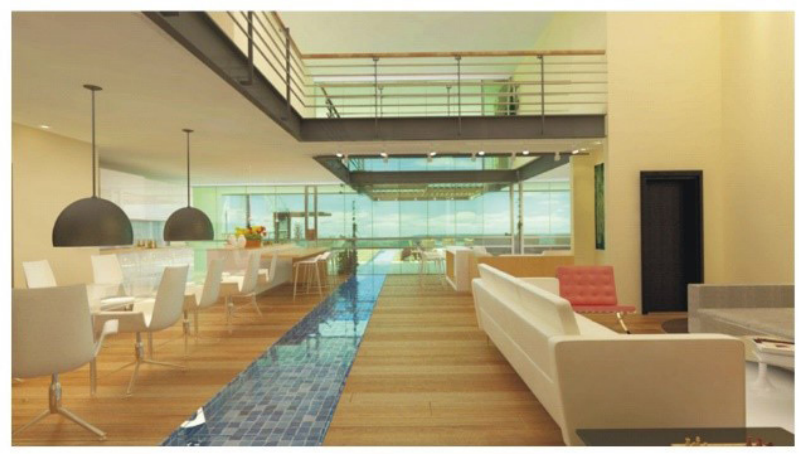

Vista interna das salas com mezanino e passarela em direção à cozinha e terraço

Fonte: Elaboração do Autor (2016)

\section{REFERÊNCIA}

MACEDO, A.L.M. Casa Camelo - Quando a casa se adequa ao meio. Dissertação de mestrado. Programa de Pós-graduação em Arquitetura, Projeto e Meio Ambiente. UFRN. Natal, 2016.

NOTA DO EDITOR (*) O conteúdo do artigo e as imagens nele publicadas são de responsabilidade do(s) autor(es). 